\title{
Increasing Survival of Splice-grafted Watermelon Seedlings Using a Sucrose Application
}

\author{
Sahar Dabirian and Carol A. Miles ${ }^{1}$ \\ Washington State University Mount Vernon Northwest Washington Research \\ and Extension Center, Mount Vernon, WA 98273
}

Additional index words. grafting success, meristem, regrowth, carbohydrate, starch accumulation

\begin{abstract}
Rootstock regrowth can prevent effective healing of grafted vegetable seedlings and outcompete the scion for light, space, and nutrients later in production. Rootstock regrowth is especially problematic for watermelon (Citrullus lanatus) because the crop is most commonly grafted using methods where meristematic tissue remains on the rootstock. The objective of this study was to test whether sucrose solutions $[0 \%$ (water control), $1 \%, 2 \%$, and $3 \%$ ] applied as a drench to rootstock seedlings before grafting would increase the survival of watermelon grafted using the splice method where both rootstock cotyledons were removed to eliminate meristem tissue and rootstock regrowth. Starch accumulation in rootstock seedlings was the highest for plants that received $3 \%$ sucrose solution $(71 \%)$, followed by plants that received $2 \%$ sucrose solution $(52 \%), 1 \%$ sucrose solution $(29 \%)$, and water $(6 \%)(P<0.0001)$. Survival $(\%)$ of splice-grafted watermelon seedlings 21 days after grafting was the greatest for plants that received $2 \%$ and $3 \%$ sucrose solution ( $89 \%$ and $82 \%$, respectively), followed by plants that received $1 \%$ sucrose solution $(78 \%)$, and was the lowest for plants that received water $(58 \%)(P<$ 0.0001). There was a significant interaction due to repeat for both starch accumulation and grafted transplant survival; however, environmental conditions were similar for both repeats: the daily average temperature was $23^{\circ} \mathrm{C}$, the relative humidity (RH) was $64 \%$ to $67 \%$, and the daily average light intensity was $224-243 \mu \mathrm{mol} \cdot \mathrm{m}^{-2} \cdot \mathrm{s}^{-1}$. Furthermore, while the vapor pressure deficit from 1:00 to 6:00 PM was $2.49 \mathrm{kPa}$ for repeat 1 and $1.42 \mathrm{kPa}$ for repeat 2 , plant survival was greater in repeat 1 than repeat 2 . These results indicate that drench applications of sucrose solution to rootstock seedlings before grafting can increase grafting success when both cotyledons are removed from the rootstock before grafting, but further research is needed to optimize the environmental conditions for the survival of grafted plants.
\end{abstract}

Watermelon (C. lanatus) seedling grafting is a means of managing abiotic stresses (e.g., high soil salinity, drought, and high temperature), reducing the reliance on chemical and fertilizer inputs, and enhancing fruit quality (Colla et al., 2010; Proietti et al., 2008). The two most commonly used grafting methods for commercial production of grafted watermelon transplants are the hole-insertion and the onecotyledon methods (Hassell et al., 2008). Both of these methods require at least one cotyledon to remain on the rootstock to ensure graft success (Bisognin et al., 2005; Hassell et al., 2008). However, to prevent rootstock growth with these methods, the meristem tissue at the

Received for publication 19 Dec. 2016. Accepted for publication 2 Mar. 2017.

Technical assistance provided by Patricia Kreider, Edward Scheenstra, Todd Coffey, inspiration provided by Muriel Nesbitt, and funding support provided by the Washington State Department of Agriculture SCBG No. K1506, USDA-NIFA SCRI No. 2011-51181-30963, Northwest Agricultural Research Foundation, Washington State Commission for Pesticide Registration, and State project WN00375-Acc. No.1008680, are gratefully acknowledged.

${ }^{1}$ Corresponding author. E-mail: milesc@wsu.edu. regrowth, such as splice grafting below both cotyledons, could significantly reduce the overall cost of producing grafted watermelon transplants and could help increase the adoption of grafted cucurbit transplants in the United States. Splice grafting, also known as top grafting or tube grafting, involves cutting the rootstock at a $45^{\circ}$ or greater angle below the cotyledons (Bausher, 2011; Oda, 1999, 2007; Rivard and Louws, 2006; Sakata et al., 2007). By cutting the rootstock below the cotyledons, meristematic tissue is completely removed, and the potential for rootstock regrowth is essentially eliminated in grafted watermelon plants. Splice grafting is the fastest, most efficient, and easiest grafting method to learn and use and therefore is the most commonly used technique for producing large numbers of solanaceous grafted plants as it is possible to graft plants 2-3 times faster than other methods (Oda, 1999, 2007; Rivard et al., 2010). Furthermore, the steps for splice grafting can easily be divided among multiple workers, further increasing the efficiency (Hartmann et al., 2002; Oda, 2007).

When both rootstock cotyledons are removed for watermelon grafting, splice-grafted plants have a significantly lower survival rate in comparison with grafting methods where at least one cotyledon remains intact on the rootstock. The remaining cotyledon functions to provide the required carbohydrates for grafting success (Memmott, 2010). Carbohydrates from the rootstock appear to be necessary for the callus formation and cell differentiation that forms the connection of vascular bundles at the graft interface, which are essential for successful graft healing (Bartolini et al., 1996; Hunter et al., 2004; Ogata et al., 2005; Rapaka et al., 2007; Schmid and Feucht, 1981). In general, carbohydrates play an important role in the construction of carbon skeletons and overall seedling metabolism by serving as a source of energy for plant cellular activity; they also influence osmotic effects (Rapaka et al., 2007). Soluble sugars are the primary form of carbohydrates in watermelon seedlings, with fructose and glucose dominating in petiole tissue, and sucrose, raffinose, and stachyose dominating in leaf tissue (Ranwala et al., 2002). Within the Cucurbit family, stachyose and sucrose are the primary carbohydrates that are translocated (Bruton et al., 1998). At the watermelon seedling stage, the cotyledons are the primary source of carbohydrates, supplying energy for metabolic processes that are encompassed in grafting (Memmott, 2010). At grafting, the growing shoot and roots become the primary carbohydrate sinks. During healing, grafted plants are placed in low light levels until the graft is healed, so the synthesis of new carbohydrates is limited and seedlings rely on stored carbohydrates for subsequent growth and development (Memmott, 2010).

Carbohydrate reserves in scion wood and rootstocks of perennial macadamia (Macadamia spp.) and litchi (Litchi chinensis) at the time of grafting have been found to be the likely cause of seasonal variation in the grafting 
success of these plants (Jones and Beaumont, 1937). Beaumont and Moltzau (1937) found that an increase in starch content of the scion wood was positively correlated with an increase in grafting success. Similarly, Rodrigues et al. (1960) found that a lack of adequate carbohydrate supply limited the grafting success of avocado (Persea americana) plants. Likewise, carbohydrate levels in rootstocks and scion plant tissue can impact callus formation and vegetative growth of newly grafted grape seedlings (Hunter et al., 2004). The role of carbohydrates in vegetable grafting has not been extensively reviewed. The development of the graft union may largely depend on the amount of carbohydrates present in the rootstock and the scion at the time of grafting. High levels of carbohydrates, as well as auxin and cytokinin, are required for successful callus formation, and there can be an interaction between rootstock and scion cultivars in carbohydrate utilization, which can affect the level of starch depletion that occurs during callus development. This phenomenon, in turn, can impact the time required for callus formation and grafting success. Bartolini et al. (1996) suggested that there is a positive relationship between carbohydrate level and callus formation in grafted grape where increased carbohydrate content of rootstock seedlings led to an increase in the survival rate of grafted transplants (Phillips et al., 2015).

Currently, commercial watermelon grafting uses relatively slow grafting methods that are labor-intensive, and for which transplants have relatively low and variable survival rates, and additionally, there is a need to manage rootstock regrowth. These factors affect the cost and adoption of grafted watermelon transplants. More research is needed to address these issues to advance the use of grafting as an affordable and effective propagation strategy for watermelon. Research with perennial crops suggests that increasing carbohydrate concentrations in grafted tissues may increase grafting success. The objective of this study was to test whether increasing carbohydrate levels through application of a sucrose solution to rootstock seedlings before grafting can increase the survival of splice-grafted watermelon transplants where both cotyledons are removed from the rootstock.

\section{Materials and Methods}

Experimental design. Two experiments were carried out at the Washington State University Mount Vernon Northwest Washington Research and Extension Center (NWREC): one to evaluate starch accumulation in watermelon rootstock stems and the other to evaluate grafting success, after four sucrose treatments, $0 \%$ (water control), $1 \%$ (1/99 g/mL), $2 \%(2 / 98 \mathrm{~g} / \mathrm{mL})$, and 3\% (3/97 $\mathrm{g} / \mathrm{mL}$ ) of sucrose in water. Both experiments were seeded at the same time, and sucrose treatments were also applied to seedlings in both experiments at the same time so as to have the same environmental conditions for plants in both experiments. For the starch-detection experiment, there were three replicates of four plants per treatment, and the experiment was repeated two times. The first repeat was carried out from 4 June to 17 June 2016, and the second repeat was carried out from 11 June to 24 June 2016. For the grafting success experiment, the design was a randomized complete block, with five replications and 12 plants per experimental unit, and the experiment was repeated two times. The first repeat was carried out from 27 May to 8 July 2016, and the second repeat was carried out from 2 June to 15 July 2016.

Plant material. For both experiments, rootstock cv. Tetsukabuto (Cucurbita maxima $\times$ Cucurbita moschata) was seeded in every other row of 72-cell trays containing a commercial potting medium (Sunshine \#3 N\&O; Sun Gro Horticulture, Agawam, MA) on 4 June (repeat 1) and 11 June (repeat 2). For the second experiment, watermelon cv. Tri-X Palomar was sown into 72-cell trays filled with the same potting medium on 27 May for repeat 1 and 2 June for repeat 2.

Sucrose application. A total of $50 \mathrm{~mL}$ sucrose solution (IB37160 Sucrose; IBI Scientific, Peosta, IA) or water was applied as a soil drench to rootstock seedlings in both experiments. The application was split into three applications, with $20 \mathrm{~mL}$ for the first and second application, and $10 \mathrm{~mL}$ for the third application. For each application, water or sucrose solution was applied between 8:00 AM and 10:00 AM to each cell every other day, with the first application $2 \mathrm{~d}$ after germination and the third application $2 \mathrm{~d}$ before grafting of seedlings in experiment 2. Seedlings were watered following common greenhouse practices on days when sucrose treatments were not applied.

Grafting methods and healing. Grafting for seedlings in experiment 2 was carried out on 17 June and 24 June for repeat 1 and 2, respectively. The splice grafting method was used for grafting, with rootstock and scion material both cut at about a $60^{\circ}$ angle below the two cotyledons. A $60^{\circ}$ angle cut provided a larger area for the connection of vascular bundles at the graft interface (Ogata et al., 2005). The two cut stem surfaces were then placed together, and a watermelon grafting clip (3 mm; Johnny's Selected Seeds, Fairfield, ME) held the grafted transplant together. Immediately after grafting, each tray was placed in a healing chamber $(0.9 \mathrm{~m}$ wide $\times$ $1.7 \mathrm{~m}$ long $\times 0.5 \mathrm{~m}$ tall) on a bench in the greenhouse, and the healing regimen described by Miles et al. (2016) was followed and is summarized here. The chamber was covered with a clear plastic $(0.15 \mathrm{~mm}$ polythene; Ginegar Plastic Products, Ginegar, Israel), a thin film of water was added to the floor of the chamber to provide $100 \% \mathrm{RH}$ inside the chamber, and the target temperature inside the chamber was $25{ }^{\circ} \mathrm{C}$. The chamber was completely covered with black fabric (Geotex 200st; Propex operating company, LLC, Chattanooga, TN) to prevent light penetration into the plants. For days 1 and 2 after grafting, the plastic of the healing chamber was kept closed, and the chamber was covered with the black fabric. The chamber was opened on day 3 , and water was added to the chamber floor so that it was barely wet, then the chamber was closed. On day 4, the chamber was opened for $15 \mathrm{~min}$, water was added to the floor of the chamber as needed, the chamber was closed, and the black fabric was folded up to expose the front side of the chamber. On day 5 , the chamber was opened for $30 \mathrm{~min}$, water was added to floor of the chamber as needed, the chamber was closed, and the black fabric was folded up to expose the sides of the chamber but the top of the chamber was covered. On day 6 , the chamber was opened for $1 \mathrm{~h}$, water was added to the floor of the chamber as needed, the chamber was closed, and the black fabric

Table 1. Starch accumulation in rootstocks after the application of $0 \%$ (water), $1 \%, 2 \%$, or $3 \%$ sucrose solution, from 4 to 17 June (repeat 1) and 11 to 24 June (repeat 2) in 2016 at Mount Vernon, WA.

\begin{tabular}{lcc}
\hline & \multicolumn{2}{c}{ Starch concn $^{\mathrm{z}}$} \\
\cline { 2 - 3 } Sucrose treatment & Repeat 1 & Repeat 2 \\
\hline $1 \%$ Sucrose & $3.0 \mathrm{c}^{\mathrm{y}}$ & $2.9 \mathrm{~b}$ \\
$2 \%$ Sucrose & $4.4 \mathrm{~b}$ & $4.5 \mathrm{a}$ \\
$3 \%$ Sucrose & $6.4 \mathrm{a}$ & $5.0 \mathrm{a}$ \\
Water (control) & $1.5 \mathrm{~d}$ & $1.3 \mathrm{c}$ \\
$P$ value & $<0.0001$ & $<0.0001$
\end{tabular}

${ }^{\mathrm{z}}$ The presence of starch was rated using a modified version of the Cornell starch-iodine starch staining test, where 1 is $0 \%, 2$ is $15 \%, 3$ is $30 \%, 4$ is $45 \%, 5$ is $60 \%, 6$ is $75 \%, 7$ is $90 \%$, and 8 is $100 \%$ starch [adapted from Blanpied and Silsby (1997)].

${ }^{\mathrm{y}}$ Mean separation letters were generated using the least squares means statement in JMP (Version 11.0 for Windows; SAS Institute, Cary, NC) with $\alpha=0.05$. Treatments followed by the same letter within a column are not significantly different.

Table 2. Survival (\%) of grafted watermelon after drench application of sucrose treatments $[1 \%$, $2 \%, 3 \%$ sucrose, and water (control)] measured 7, 10, 14, and $21 \mathrm{~d}$ after grafting at Mount Vernon, WA; repeat 1 was from 27 May to 8 July and repeat 2 was from 2 June to 15 July 2016.

\begin{tabular}{lccll}
\hline Sucrose treatment & \multicolumn{4}{c}{ Survival $^{\mathrm{z}}(\%)$} \\
\hline Repeat 1 & $7 \mathrm{~d}$ & $10 \mathrm{~d}$ & $14 \mathrm{~d}$ & $21 \mathrm{~d}$ \\
1\% Sucrose & 100 & 100 & 85 & 78 \\
2\% Sucrose & 100 & 100 & 95 & 90 \\
3\% Sucrose & 100 & 97 & 93 & 87 \\
Water (control) & 100 & 97 & 77 & 68 \\
$P$ value & & 0.19 & 0.11 & 0.09
\end{tabular}

\begin{tabular}{lllll} 
Repeat 2 & \multicolumn{5}{c}{ Survival (\%) } \\
$1 \%$ Sucrose & 99 & 93 & $88 \mathrm{a}^{\mathrm{y}}$ & $77 \mathrm{a}$ \\
$2 \%$ Sucrose & 98 & 93 & $90 \mathrm{a}$ & $88 \mathrm{a}$ \\
$3 \%$ Sucrose & 98 & 90 & $81 \mathrm{a}$ & $76 \mathrm{a}$ \\
Water (control) & 99 & 77 & $62 \mathrm{~b}$ & $48 \mathrm{~b}$ \\
$P$ value & 0.85 & 0.06 & 0.005 & 0.004 \\
\hline
\end{tabular}

${ }^{\mathrm{z}}$ Survival data for the first repeat were transformed for statistical analysis (arcsin of square root transformation was the most appropriate); means are presented in their original units.

${ }^{\mathrm{y}}$ Mean separation letters were generated using the least squares means statement in JMP (Version 11.0 for Windows; SAS Institute, Cary, NC) with $\alpha=0.05$. Treatments followed by the same letter within a column are not significantly different. Means without letters indicate that no statistical differences were found. 

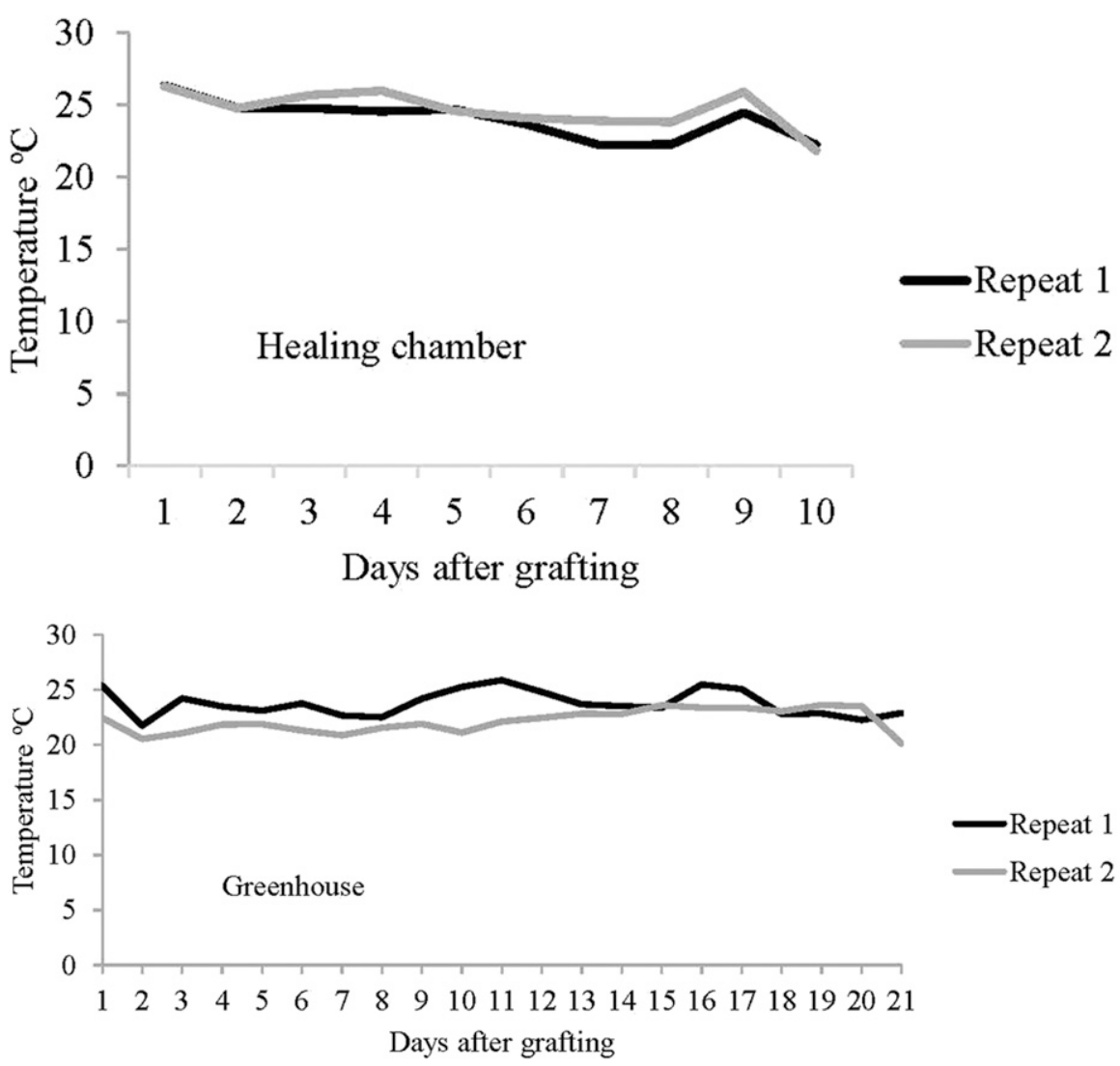

Fig. 1. Temperature $\left({ }^{\circ} \mathrm{C}\right.$ ) in the healing chamber (top) for $10 \mathrm{~d}$ and in the greenhouse (bottom) for $21 \mathrm{~d}$ after grafting, from 17 June to 8 July (repeat 1) and 24 June to 15 July (repeat 2) in 2016 at Mount Vernon, WA. Data were recorded every 15 min (Onset HOBO, Bourne, MA).
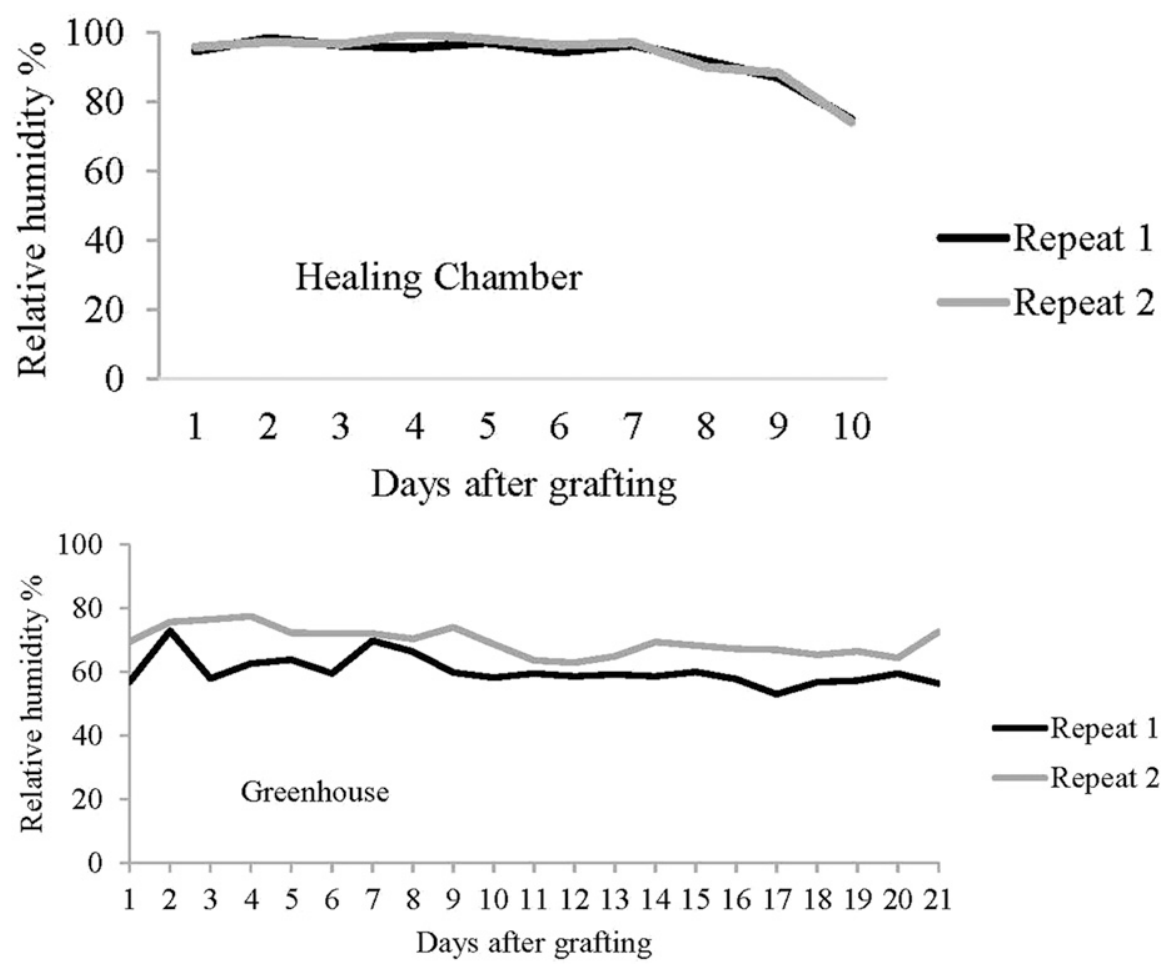

Fig. 2. Relative humidity (\%) in the healing chamber (top) for $10 \mathrm{~d}$ and in the greenhouse (bottom) for $21 \mathrm{~d}$ after grafting, from 17 June to 8 July (repeat 1) and 24 June to 15 July (repeat 2) in 2016 at Mount Vernon, WA. Data were recorded every 15 min (Onset HOBO, Bourne, MA). was removed entirely. On days 7 and 8 , the chamber was opened for 3 and $6 \mathrm{~h}$, respectively, water was added to the floor of the chamber as needed, and the chamber was closed. Plants were removed from the chamber on day 9 and placed on the greenhouse bench and watered.

Plant starch detection and grafting survival. For each treatment in experiment 1 , rootstock seedlings were destructively sampled $1 \mathrm{~d}$ before seedlings in experiment 2 were grafted, and starch accumulation was measured. A 2-cm segment of hypocotyl of each seedling was cut midway between the soil surface and cotyledons, and then each segment was cut in half longitudinally. The 2-cm longitudinal segments were stained with I2/KI solution ( $5 \mathrm{~g} \mathrm{KI} 0.5 \mathrm{~g} \mathrm{I}_{2}, 500 \mathrm{~mL}$ $\mathrm{H}_{2} \mathrm{O}$ ) for $2 \mathrm{~min}$, followed by an $80 \%$ ethanol wash (20/80) (Alvarado et al., 2012). A dark blue precipitate was observed in the tissue where the starch was present. The presence of starch was rated using a modified version of the Cornell starch-iodine starch staining test, such that 1 is $0 \%, 2$ is $15 \%, 3$ is $30 \%, 4$ is $45 \%, 5$ is $60 \%, 6$ is $75 \%, 7$ is $90 \%$, and 8 is $100 \%$ starch [adapted from Blanpied and Silsby (1997)]. In experiment 2, survival was assessed for grafted plants in each replicate treatment $7,10,14$, and $21 \mathrm{~d}$ after grafting. Graft survival was defined as turgidity of scion leaves and stems; failed grafted plants had entirely wilted scion leaves and stems.

Environmental conditions. The temperature, $\mathrm{RH}$, and light in the healing chamber and on the bench in the greenhouse next to the healing chamber (where plants were placed when they were taken out of the chamber) were measured every 15 min (Onset HOBO, Bourne, MA). To better understand the impact of temperature and $\mathrm{RH}$ on graft survival, the vapor pressure deficit (VPD) was measured in the greenhouse for each repeat using the equation: [1 $-(\mathrm{RH} /$ $100)] *$ saturated vapor pressure (SVP) (Campbell and Norman, 1998).

Data analysis. Data were subjected to analysis of variance using JMP software (version 11.0 for Windows; SAS Institute, Cary, NC). The sucrose treatments and water control were explanatory variables, whereas starch accumulation and grafting survival were response variables. The survival data for grafted transplants in the first repeat were transformed using an arcsine of square root transformation to meet assumptions of normality and equality of the variance. Microsoft Excel (Microsoft Office 2013 for Windows; Microsoft Corporation, Redmond, WA) was used to calculate daily averages of measured environmental factors.

\section{Results and Discussion}

Starch detection. Starch accumulation in the rootstock differed because of sucrose treatment in both repeats $(P<0.0001)$, and there was also a difference due to repeat $(P=$ 0.02 ) and an interaction between treatment and repeat $(P=0.02)$. Overall, starch accumulation 
in rootstock seedlings was the highest for plants that received 3\% sucrose solution (71\%), followed by plants that received $2 \%$ sucrose solution $(52 \%)$, $1 \%$ sucrose solution $(29 \%)$, and water $(6 \%)$. Starch accumulation was similar in the two repeats for $2 \%$ sucrose (4.4-4.5 rating, $\approx 51 \%$ to $53 \%$ starch), $1 \%$ sucrose (2.9-3.0 rating, $\approx 29 \%$ to $30 \%$ starch), and water (1.3-1.5 rating, $\approx 5 \%$ to $8 \%$ starch), but was greater for $3 \%$ sucrose in repeat 1 (6.4 rating, $\approx 81 \%$ starch) than in repeat 2 (5.0 rating, $\approx 60 \%$ starch) (Table 1 ). In repeat 1 , starch accumulation was greater for plants treated with 3\% sucrose and lesser for plants treated with water, and was intermediate for plants treated with $2 \%$ or $1 \%$ sucrose. In repeat 2 , starch accumulation was the greatest for plants treated with $3 \%$ or $2 \%$ sucrose solution, intermediate for plants treated with $1 \%$ sucrose, and the lowest for plants treated with water. Thus, overall starch accumulation in rootstock seedlings after drench application of sucrose solution was $30 \%$ to $80 \%$, whereas starch accumulation in seedlings treated with water was $5 \%$ to $8 \%$. These results indicate that sucrose solution applied as a soil drench was taken up by the rootstock seedlings and increased seedling starch concentrations.

Grafted plant survival. Survival (\%) of splice-grafted watermelon differed because of sucrose treatment, repeat, and days after grafting $(P<0.0001$ for all). There was also a significant interaction between sucrose treatment and days after grafting $(P=$ $0.0005)$, and between sucrose treatment and repeat $(P=0.02)$. Survival of splice-grafted watermelon seedlings $21 \mathrm{~d}$ after grafting was the greatest for plants that received $2 \%$ and $3 \%$ sucrose solution $(89 \%$ and $82 \%$, respectively), followed by plants that received $1 \%$ sucrose solution $(78 \%)$, and was the lowest for plants that received water $(58 \%)(P<$ 0.0001 ). Survival of grafted plants that received sucrose solution was $85 \%$ in repeat 1 and $80 \%$ in repeat 2 , whereas survival of grafted plants that received water was $68 \%$ in repeat 1 and $48 \%$ in repeat 2 . In repeat 1 , due to variation among replicates, there was no significant difference in plant survival because of treatment at each measurement date, even though final plant survival was $22 \%$ greater with $2 \%$ sucrose solution as compared with water (Table 2). Plant survival declined over the course of the study; there was no loss in grafted plants at $7 \mathrm{~d}(100 \%$ survival on average), but plant survival declined to $98 \%$ on average at $10 \mathrm{~d}, 88 \%$ on average at $14 \mathrm{~d}$, and $62 \%$ on average at $21 \mathrm{~d}$ after grafting. In repeat 2 , there was no significant difference in plant survival because of sucrose treatments at $7 \mathrm{~d}(99 \%$ on average) or $10 \mathrm{~d}(88 \%$ on average) after grafting; but at $14 \mathrm{~d}$ after grafting, survival of plants treated with water $(61 \%)$ was lower than that of plants treated with sucrose solution ( $87 \%$ on average). Survival declined even further at $21 \mathrm{~d}$ after grafting for plants treated with water (48\%) compared with plants treated with sucrose ( $80 \%$ on average).

These results indicate that a drench application of a sucrose solution to rootstock seedlings before grafting can increase grafting success when both cotyledons are removed from the rootstock before grafting. Sucrose solutions can provide a carbohydrate source for the support of plant growth (Dormer and Street, 1949; Ferguson et al., 1958; Thomas and Weir, 1967; White, 1934, 1940), and in the current study, increased starch levels in rootstock tissue appeared to enhance watermelon graft survival when both cotyledons were removed from the rootstock. Sucrose is commonly used in the medium for plant tissue culture to enhance plant growth (Fuentes et al., 2000; Ferguson, 1958; Li et al., 2015) and has been reported to serve as an osmotic regulator in addition to a carbohydrate source (Biahoua and Bonneau, 1999). Sucrose may improve callus formation and connectivity of vascular bundles at the graft interface (Hunter et al., 2004; Ogata et al., 2005). Phillips et al. (2015) suggested that in grafted grapes, an increased concentration of soluble sugars, which consisted primarily of sucrose in rootstock seedlings, could increase the survival of grafted plants. More studies are needed to evaluate different levels of sucrose concentration to optimize watermelon grafting success. Additionally, larger studies that include more plants per replicate, more replicates, and more repeats will likely provide more statistically significant results.

Environmental conditions. Daily average temperature and $\mathrm{RH}$ in the healing chamber and in the greenhouse were similar for both repeats (Figs. 1 and 2). Light intensity measured inside the chamber was also similar for both repeats, but differed after plants were placed on the bench in the greenhouse from days 9 to 21 (Fig. 3). Overall, the daily average temperature inside the chamber was $24-26^{\circ} \mathrm{C}$, whereas the daily average temperature in the greenhouse was $21-24^{\circ} \mathrm{C}$. In the first $3 \mathrm{~d}$ after grafting, when the plastic of the chamber was closed and the chamber was entirely covered with black fabric, the daily average temperature inside the chamber for repeats 1 and 2 was $25-26{ }^{\circ} \mathrm{C}$, and the temperature in the greenhouse was $21-$ $24^{\circ} \mathrm{C}$. The daily average $\mathrm{RH}$ during this time for both repeats was $97 \%$ inside the chamber and $63 \%$ to $74 \%$ in the greenhouse. The daily average light intensity in the chamber for both repeats was $1.2 \mu \mathrm{mol} \cdot \mathrm{m}^{-2} \cdot \mathrm{s}^{-1}$. For days 4 to 6 , when plants in the chamber were exposed to the greenhouse environment for $1 \mathrm{~h}$ or less each day and the chamber was partially covered with black fabric, the daily average temperature inside the chamber was $24-25^{\circ} \mathrm{C}$, and the temperature in the greenhouse was $22-23{ }^{\circ} \mathrm{C}$. The daily average $\mathrm{RH}$ during this time was $96 \%$ to $98 \%$ inside the chamber and $62 \%$ to $74 \%$ in the greenhouse. The daily average light intensity inside the chamber was $6.6-7.2 \mu \mathrm{mol} \cdot \mathrm{m}^{-2} \cdot \mathrm{s}^{-1}$. For 7 to $9 \mathrm{~d}$ after grafting, when plants in the chamber were exposed for an average of $5 \mathrm{~h}$ each day to the greenhouse environment and the black fabric was removed, the temperature inside the chamber was $23-25^{\circ} \mathrm{C}$, and the temperature in the greenhouse was $23-21^{\circ} \mathrm{C}$. The

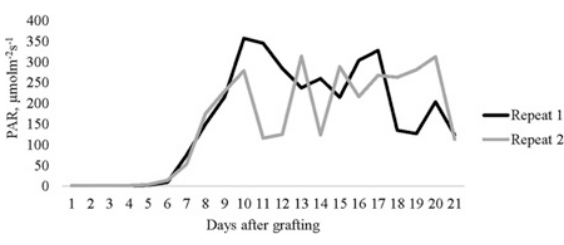

Fig. 3. Light intensity of photosynthetically active radiation $\left(P A R, \mu \mathrm{mol} \cdot \mathrm{m}^{-2} \cdot \mathrm{s}^{-1}\right)$ in the healing chamber for $9 \mathrm{~d}$ and in the greenhouse for 10 to $21 \mathrm{~d}$ after grafting, from 17 June to 8 July (repeat 1) and 24 June to 15 July (repeat 2) in 2016 at Mount Vernon, WA. Data were recorded every $15 \mathrm{~min}$ (Onset HOBO, Bourne, MA).

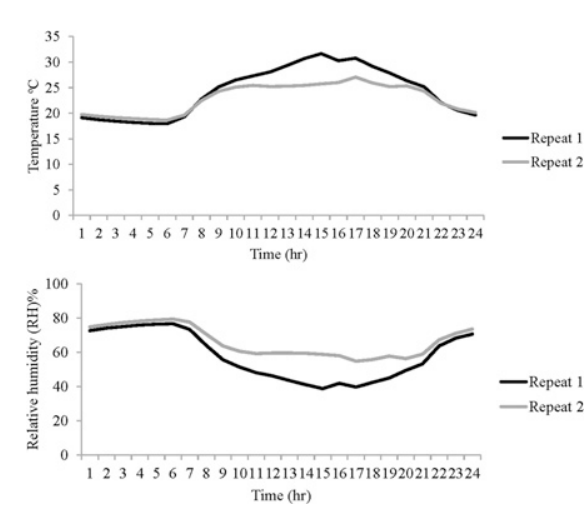

Fig. 4. Average daily temperature (top) and relative humidity (\%) (bottom) each hour in the greenhouse for days 10-21 (when plants were on the greenhouse bench), from 27 June to 8 July (repeat 1) and 4 to 15 July (repeat 2) in 2016 at Mount Vernon, WA. Data were recorded every 15 min (Onset HOBO, Bourne, MA).

daily average $\mathrm{RH}$ during this time for both repeats was $92 \%$ inside the chamber and $65 \%$ to $72 \%$ in the greenhouse. The daily average light intensity in the chamber was similar for both repeats, and was $147 \mu \mathrm{mol} \cdot \mathrm{m}^{-2} \cdot \mathrm{s}^{-1}$ in repeat 1 and $152 \mu \mathrm{mol} \cdot \mathrm{m}^{-2} \cdot \mathrm{s}^{-1}$ in repeat 2 . For 10 to $21 \mathrm{~d}$, when the plants were on the greenhouse bench, the daily average temperature in the greenhouse for both repeats was $23{ }^{\circ} \mathrm{C}$ and the RH was $64 \%$ to $67 \%$. The daily average light intensity in the greenhouse was $243 \mu \mathrm{mol} \cdot \mathrm{m}^{-2} \cdot \mathrm{s}^{-1}$ in repeat 1 and 224 $\mu \mathrm{mol} \cdot \mathrm{m}^{-2} \cdot \mathrm{s}^{-1}$ in repeat 2 . During this period, the average temperature and $\mathrm{RH}$ each hour were similar for both repeats from 10:00 PM to 7:00 AM but differed from 1:00 to 6:00 PM (Fig. 4). For repeat 1 , the temperature reached a maximum of $32^{\circ} \mathrm{C}$ and $\mathrm{RH}$ reached a minimum of $43 \%$ during the afternoon, whereas for repeat 2 , maximum temperature was $27{ }^{\circ} \mathrm{C}$ and minimum RH was $60 \%$. The VPD from 10:00 PM to 7:00 AM was $0.60 \mathrm{kPa}$ for repeat 1 and $0.57 \mathrm{kPa}$ for repeat 2 , whereas from 1:00 to 6:00 PM the VPD was $2.49 \mathrm{kPa}$ for repeat 1 and $1.42 \mathrm{kPa}$ for repeat 2. In general, the ideal range for VPD is 0.40 to 1.34 , but can vary based on crop species and the stage of growth (Argus Control Systems LTD, 2009). In the current study, the VPD and plant survival were the greatest for repeat 1; thus, VPD did not account for the lower plant survival in repeat 2 . 


\section{Conclusions}

The cotyledon is a carbohydrate source and plays a key role in grafting success for watermelon and other cucurbit crops (Memmott, 2010). When both cotyledons are removed, as in the splice grafting method, this can reduce watermelon grafting success, suggesting a correlation between carbohydrate status and seedling survival in grafted watermelon. In the current study, when sucrose solution was applied to rootstock seedlings as a soil drench before grafting, starch accumulated in the rootstock stem, and the survival of plants grafted with the splice technique was $83 \%$ on average, as compared with $58 \%$ survival for grafted plants that received water.

Grafting watermelon, and other cucurbit crops, using the splice method where both cotyledons are removed, could significantly decrease costs of grafting as this would eliminate the need for extra attention and time when cutting the watermelon rootstock for grafting. In addition, rootstock regrowth would essentially be eliminated as the rootstock meristem tissue would be removed when both cotyledons are removed. This could help increase the adoption of grafted watermelon plants as there would be no need to scout fields and remove rootstock regrowth. Additional studies are needed to investigate the optimum sucrose solution concentration, timing of application, and whether sucrose solution should be applied to both rootstock and scion seedlings to increase success in splice-grafting watermelon seedlings. Furthermore, research is needed to determine the optimal environmental conditions for the survival of splice grafted watermelon plants. It may also be useful to test different angles of cutting the seedling stems as well as the distance of the cut below the cotyledons. Moreover, splicegrafted seedlings should be evaluated in field studies to ensure they are vigorous with good yield and high fruit quality. In the current study, a standard healing regimen was followed based on the one-cotyledon grafting method. More studies are needed to determine the optimum temperature, $\mathrm{RH}$, and light levels for each day of the healing regimen for watermelon grafted with the splice method.

\section{Literature Cited}

Alvarado, V.Y., D. Odokonyero, O. Duncan, T.E. Mirkov, and H.B. Scholthof. 2012. Molecular and physiological properties associated with zebra complex disease in potatoes and its relation with candidatus liberibacter contents in psyllid vectors. PLoS One 7:e37345<http:// www.plosone.org $>$.

Argus Controls Sytems Ltd. 2009. Understanding and using VPD. Argus application note, Argus Control Systems Ltd., White Rock, Canada. 27 Feb. 2017. <http://www.arguscontrols.com/ resources/VPD_Application_Note.pdf>.

Bartolini, G., P. Pestelli, M.A. Toponi, and G. Di Monte. 1996. Rooting and carbohydrate avail- ability in Vitis 140 Ruggeri stem cuttings. Vitis 35:11-14.

Bausher, M. 2011. Grafting technique to eliminate rootstock suckering of grafted tomatoes. HortScience 46:596-597.

Beaumont, J.H. and R.T. Moltzau. 1937. Nursery propagation and top working of the macadamia. Hawaii Agr. Expt. Sta. Circ. No. 13.

Biahoua, A. and L. Bonneau. 1999. Control of in vitro somatic embryogenesis of the spindle tree (Euonymus europaeus L.) by the sugar type and the osmotic potential of the culture medium. Plant Cell Rpt. 19:185-190.

Bisognin, D.A., L. Velasquez, and I. Widders. 2005. Cucumber seedling dependence on cotyledonary leaves for early growth. Pesq. Agropec. Bras. Brasilia 40:531-539.

Blanpied, G.D. and K.J. Silsby. 1997. Predicting harvest date windows for apples. Cornell Univ. Coop. Ext. Bul. 221.

Bruton, B.D., V.M. Russo, J. Garcia-Jimenez, and M.E. Miller. 1998. Carbohydrate partitioning, cultural practices, and vine decline diseases of Cucurbits. Cucurbit 98:189-200.

Campbell, G.S. and J.M. Norman. 1998. An introduction to environmental biophysics. 2nd ed. Springer-Verlag, New York, NY.

Choi, D.C., S.W. Kwon, B.R. Ko, and J.S. Choi. 2002. Using chemical controls to inhibit axillary buds of Lagenaria as rootstock for grafted watermelon (Citrullus lanatus). Acta Hort. 588:43-48.

Colla, G., C.M.C. Suarez, M. Cardarelli, and Y. Rouphael. 2010. Improving nitrogen use efficiency in melon by grafting. HortScience 45:559-565.

Davis, A.R., P. Perkins-Veazie, Y. Sakata, S. Lopez-Galarza, J.V. Maroto, S. Lee, Y. Huh, Z. Sun, A. Miguel, S.R. King, R. Cohen, and J. Lee. 2008. Cucurbit grafting. Crit. Rev. Plant Sci. 27:50-74

Dormer, K.J. and H.E. Street. 1949. The carbohydrate nutrition of tomato roots. Ann. Bot 13:199-217.

Ferguson, J.D. 1958. Studies on the carbohydrate metabolism of excised roots of Lycopersicum esculentum Mill. Univ. of Wales, Cardiff, $\mathrm{PhD}$ Diss.

Ferguson, J.D., H.E. Street, and S.B. David. 1958. The carbohydrate nutrition of tomato roots. The promotion and inhibition of excised root growth by various sugars and sugar alcohols. Ann. Bot. 22:513-523.

Fuentes, S.R., M.B. Calheiros, L. Manetti-Filho, and L.G. Vieira. 2000. The effects of silver nitrate and different carbohydrate sources on somatic embryogenesis in Coffea canephora. Plant Cell Tissue Organ Cult. 60:5-13.

Hartmann, H.T., D.E. Kester, F.T. Davies, Jr., and R.L. Geneve. 2002. Plant propagation and principles. 7th ed. Prentice Hall, Upper Saddle River, NJ.

Hassell, R.L., F. Memmott, and D.G. Liere. 2008. Grafting methods for watermelon production. HortScience 43:1677-1679.

Hunter, J.J., C.G. Volschenk, D.J. le Roux, and L. Adams. 2004. Plant material quality: A compilation of research. ARC Infruitec-Nietvoorbij, Stellenbosch, South Africa.

Jones, W.W. and J.H. Beaumont. 1937. Carbohydrate accumulation in relation to vegetative propagation of the Litchi. Science 86:313.

Li, X., S. Huang, Y. Han, and H. Yuan. 2015. Plant regeneration of Iris germanica L. from shoot apexes via an improved somatic embryogenesis protocol. HortScience 50:1045-1048.
Memmott, F.D. 2010. Refinement of innovative watermelon grafting methods with appropriate choice of developmental stage, rootstock type, and root treatment to increase grafting success. Clemson Univ., Clemson, MS Thesis.

Memmott, F.D. and R.L. Hassell. 2010. Watermelon (Citrullus lanatus) grafting method to reduce labor cost by eliminating rootstock side shoots. Acta Hort. 871:389-394. (abstr.).

Miles, C., L. Hesnault, S. Johnson, P. Kreider, and S. Dabirian. 2016. Vegetable grafting: Watermelon. Wash. State Univ. Ext. Pub. FS100E.

Oda, M. 1999. Grafting of vegetables to improve greenhouse production. Food Fert. Technol. Ctr. Ext. Bul. 480:1-11.

Oda, M. 2007. Vegetable grafting in Japan. Proc. XXVII IHC on Global Hort.: Diversity and Harmony. Acta Hort.759:175-180.

Ogata, T., Y. Kabashima, S. Shiozaki, and S. Horiuchi. 2005. Regeneration of the vascular bundle at the graft interface in auto- and heterografts with juvenile nucellar seedlings of satsuma mandarin, yuzu and trifoliate orange. J. Jpn. Soc. Hort. Sci. 74:214-220.

Proietti, S., Y. Rouphael, G. Colla, M. Cardarelli, M. De Agazio, M. Zacchini, E. Rea, S. Moscatello, and A. Battistelli. 2008. Fruit quality of mini-watermelon as affected by grafting and irrigation regimens. J. Sci. Food Agr. 88:1107-1114.

Phillips, N., A. Reynolds, and F. Di Profio. 2015. Nonstructural carbohydrate concentrations in dormant grapevine scionwood and rootstock. HortTechnology 25:536-550.

Ranwala, N.K.D., D.R. Decoteau, A.P. Ranwala, and W.B. Miller. 2002. Changes in soluble carbohydrates during phytochrome-regulated petiole elongation in watermelon seedlings. Plant Growth Regulat. 38:157-163.

Rapaka, M.K., J.E. Faust, J.M. Dole, and E.S Runkle. 2007. Diurnal carbohydrate dynamics affect postharvest ethylene responsiveness in portulaca (Portulaca grandiflora) unrooted cuttings. Postharvest Biol. Technol. 44:293299.

Rivard, C. and F.J. Louws. 2006. Grafting for disease resistance in heirloom tomatoes. North Carolina State Univ. Coop. Ext. Serv. 675.

Rivard, C.L., O. Sydorovych, S. O’Connell, M.M Peet, and F.J. Louws. 2010. An economic analysis of two grafted tomato transplant production systems in the United States. HortTechnology 20:794-803.

Rodrigues, J., G.F. Ryan, and E.F. Frolich. 1960 Some factors influencing grafting success with avocados. California Avocado Soc. Yearbook 44:89-92.

Sakata, Y., T. Ohara, and M. Sugiyama. 2007. The history and present state of the grafting of cucurbitaceous vegetables in Japan. Acta Hort. 731:159-170.

Schmid, P.P. and W. Feucht. 1981. Differentiation of sieve tubes in compatible and incompatible Prunus graftings. Sci. Hort. 15:349-354.

Thomas, D.R. and N.R. Weir. 1967. A note on sucrose and glucose uptake by apical segments of tomato roots. New Phytol. 66:125129

White, P.R. 1934. Potentially unlimited growth of excised tomato root tips in a liquid medium. Plant Physiol. 9:585-600.

White, P.R. 1940. Sucrose vs. dextrose as carbohydrate source for excised tomato roots. Plant Physiol. 15:355-358. 